Supplement of

\title{
Aircraft-based measurements of High Arctic springtime aerosol show evidence for vertically varying sources, transport and composition
}

Megan D. Willis et al.

Correspondence to: Megan D. Willis (megan.willis@mail.utoronto.ca)

The copyright of individual parts of the supplement might differ from the CC BY 4.0 License. 


\section{Supplementary Methods}
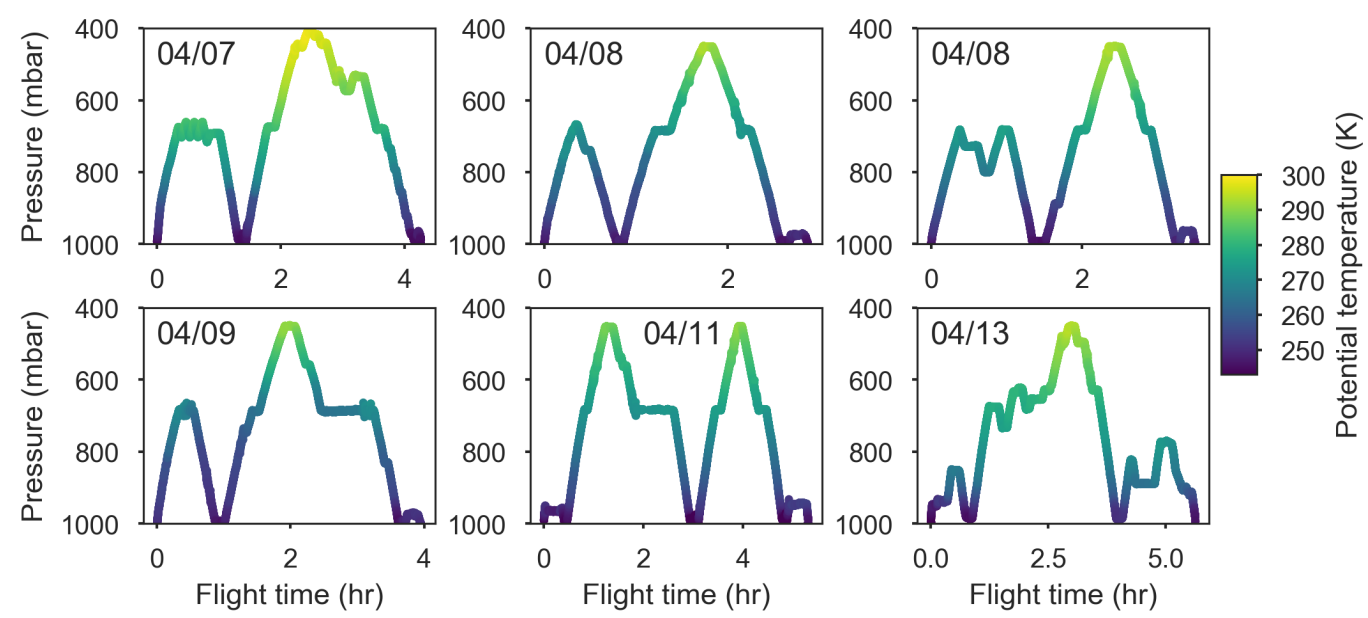

Figure S1: Pressure versus time since take-off, coloured by measured potential temperature, for all six High Arctic NETCARE flights during 7 - 13 April 2015. Note that the full flight is shown in each case; however, this work only considers measurements made at pressures higher than $\sim 640$ mbar (i.e., below $\sim 3.5 \mathrm{~km}$ ) because the ToF-AMS was not run at lower ambient pressures.

\begin{tabular}{cccc}
\hline & & April 7, 8 (leg 1), 9, 11 & April 8 (leg 2), 13 \\
\hline Menu 1 & Mode & Ensemble MS, SP laser on & Ensemble MS, SP laser on \\
& Duration & 10s (5s open, 5s closed) & 10s (5s open, 5s closed) \\
Menu 2 & Mode & Ensemble MS, SP laser off & Ensemble MS, SP laser off \\
& Duration & 10s (5s open, 5s closed) & 10s (5s open, 5s closed) \\
Menu 3 & Mode & epToF, SP laser on & Event Trigger, SP laser on \\
& Duration & $10 \mathrm{~s}$ & $10 \mathrm{~s}$ \\
\hline
\end{tabular}

Table S1: Summary of ToF-AMS Operation Modes during NETCARE 2015 

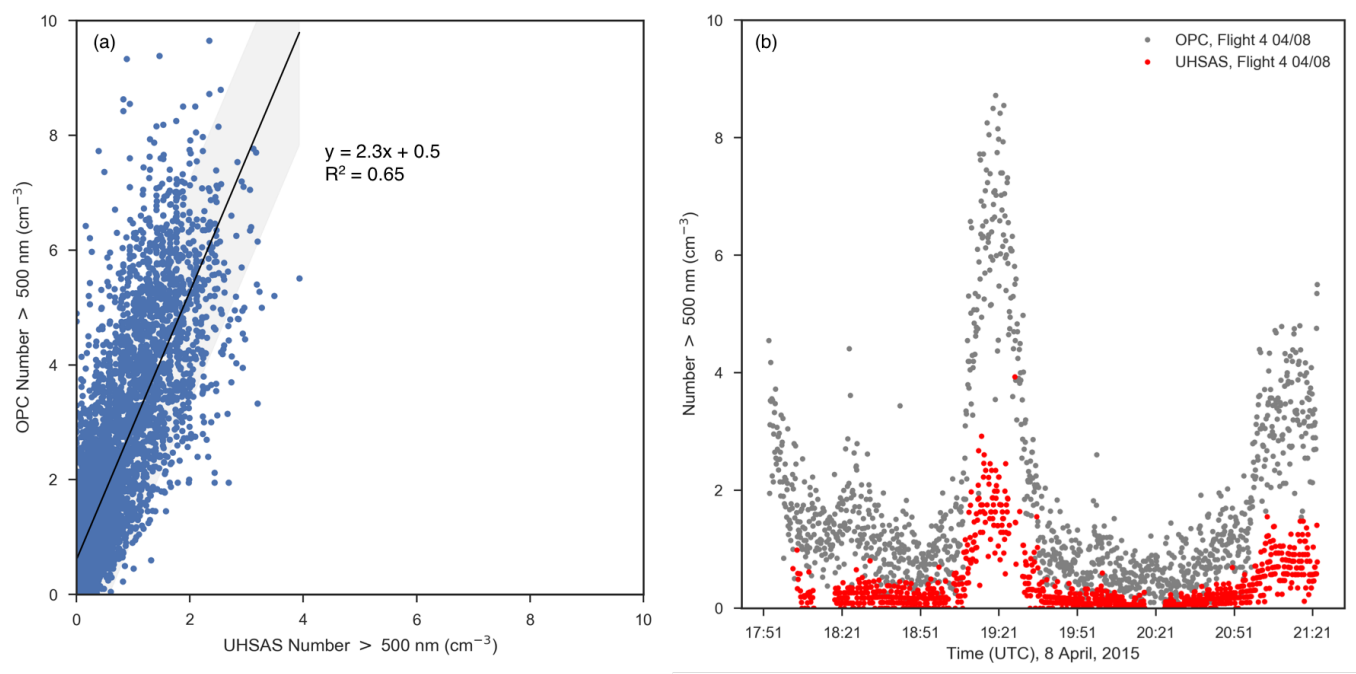

Figure S2: Comparison between the number of particles greater than $500 \mathrm{~nm}$ measured by the UHSAS and OPC. (a) For all observations, average to 10 second time intervals. (b) An example time series comparison for Flight 4 on 8 April 2015, also at 10 second time resolution.

Comparison of particle instruments. Two main issues arose when comparing ToF-AMS particle mass with that estimated from other, size-resolved measurements of particle concentration. First, it is clear that the AMS underestimates aerosol mass in the presence of sea salt. Second, when sea salt was not important, the ToF-AMS gives a higher mass concentration than that predicted by the UHSAS by approximately a factor of two. A similar discrepancy between ToF-AMS aerosol mass and UHSAS estimated mass concentrations was discussed in Willis et al. (2017) for measurements from NETCARE 2014. The source of this discrepancy is discussed further here.

In addition to the two issues noted above, it appears that the UHSAS may not be counting the very low concentrations of larger particles accurately, and giving approximately a factor of two lower particle numbers above $500 \mathrm{~nm}$ compared to an optical particle counter (OPC) that was also sampling during the NETCARE flights (Figure S2). Unfortunately the OPC was not integrated onto the Polar6 for NETCARE 2014, and so is not included in the instrumental comparisons described by Leaitch et al. (2016) and a quantitative laboratory comparison between the UHSAS and OPC is not available. The OPC periodically provides spuriously high concentrations of particles between $250-400 \mathrm{~nm}$ and so we restrict the comparison to sizes above $500 \mathrm{~nm}$.

Total particle concentrations above 4 and $10 \mathrm{~nm}$ were measured with two condensation particle counters (TSI CPC 3776 and 3772). Total number concentrations from the CPCs and the number of particles larger than $85 \mathrm{~nm}$ from the UHSAS agreed reasonably because the number concentrations of Arctic haze particles are dominated by particles larger than $85 \mathrm{~nm}$ (Figure S3). Thus, there is no indication of a significant bias in the particle number concentrations measured with the UHSAS. The discrepancy between the OPC and UHSAS for particles larger than $500 \mathrm{~nm}$ can still happen as the number of particles larger than 500 $\mathrm{nm}$ make very small relative contributions to the total particle number concentration. While the number concentrations of particles above $500 \mathrm{~nm}$ are small, they contribute significant amounts of mass (e.g., up to $\sim 1 \mathrm{ug} / \mathrm{m}^{3}$ depending on the assumed density). For the above reasons, we have used UHSAS observations between $100-500 \mathrm{~nm}$ and OPC observations above $500 \mathrm{~nm}$. 

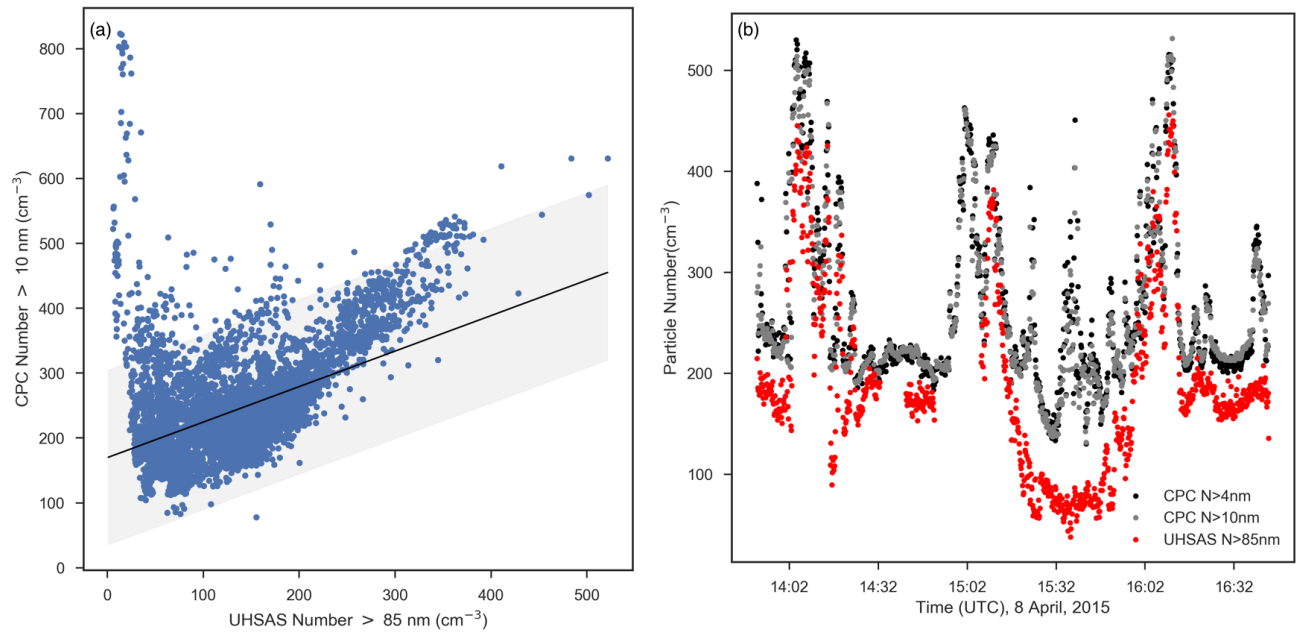

Figure S3: Comparison between the number of particles greater than $10 \mathrm{~nm}$ measured by the CPC and the number of particles greater than $85 \mathrm{~nm}$ measured by the UHSAS, averaged to 10 second time intervals. (a) For all observations when the difference in concentration measured by the two CPCs was negligible. (b) An example time series comparison for Flight 3 on 8 April 2015.

Assuming a particle density of $1.5 \mathrm{~g} / \mathrm{cm}^{3}$, we compared total non-refractory aerosol mass from the ToF-AMS with the mass estimated from combined data from the UHSAS and OPC (i.e., the number of particles between $100-500 \mathrm{~nm}\left(\mathrm{~N}_{100-500}\right)$ derived from UHSAS observations and the number greater than $500 \mathrm{~nm}\left(\mathrm{~N}_{>500}\right)$ from the OPC. This comparison illustrates that the ToF-AMS does not reflect aerosol mass compared to the OPC and UHSAS when sea salt is an important component and overestimates aerosol mass compared to the OPC and UHSAS by approximately a factor of two at other times (Figure S4). This discrepancy likely arises from biases in both the UHSAS and ToF-AMS measurements. Comparison of the UHSAS volume size distributions with that measured at the Alert Observatory was possible for short periods when the aircraft flew low in the area (i.e., between 60-200 m above ground level). These comparisons suggest that the UHSAS underestimates particle volume between $250-500 \mathrm{~nm}$ by approximately $20 \%$.

Owing to the discrepancies discussed above the absolute particle mass concentrations presented in this work should be treated with caution. However, we believe that these discrepancies do not prevent us from using these data to make the interpretations described in this work, which rely particularly on relative changes in aerosol composition with altitude. 

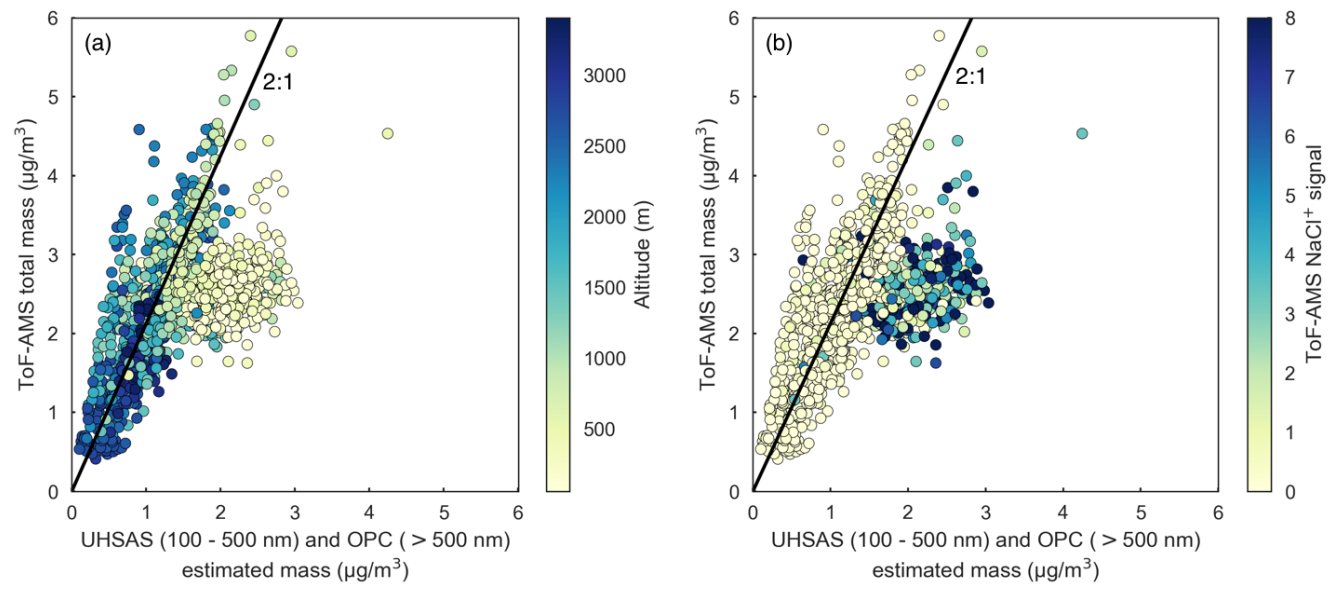

Figure S4: Comparison between ToF-AMS total non-refractory aerosol mass and aerosol mass estimated from the UHSAS and OPC particle size distributions, assuming a particle density of $1.5 \mathrm{~g} / \mathrm{cm}^{3}$ and coloured by (a) sampling altitude and (b) ToF-AMS uncalibrated signal for sea salt. 
Single particle measurements.

\begin{tabular}{cc}
\hline ROI $(\mathrm{m} / \mathrm{z})$ & Threshold (Ions/Extraction) \\
\hline 46 & 1 \\
64 & 1 \\
$45-150$ & 3 \\
\hline
\end{tabular}

Table S2: Event Trigger Regions of Interest

(a)

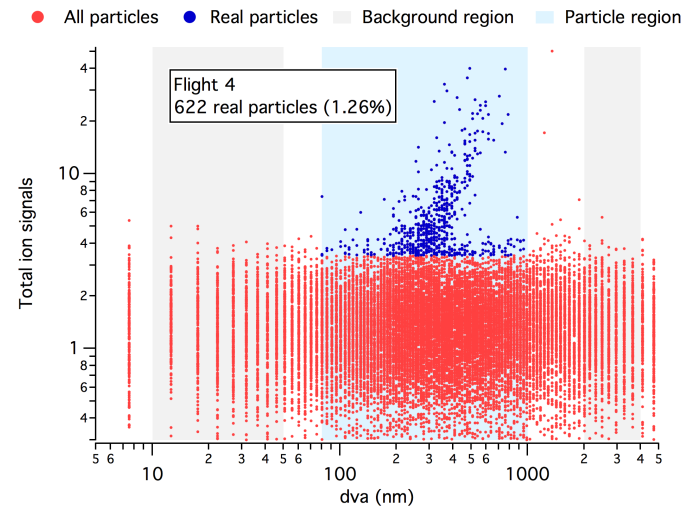

(b)

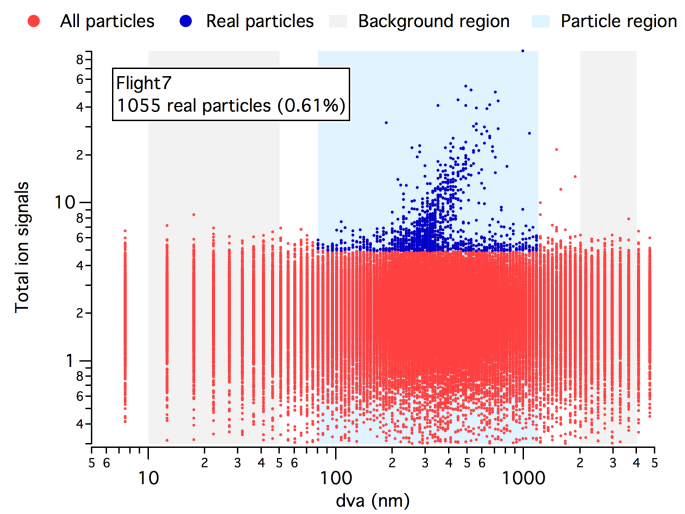

Figure S5: (a) Total aerosol ion signal, excluding air peaks, for all ETSP mass spectra collected during flight 4 on 8 April, 2015 (red points). Blue points represent particle spectra identified as "real" based on setting a threshold of the mean aerosol ion signal in background regions (grey shading) plus three times its standard deviation. Blue shading indicates the size range over which "real" particles are selected. $622 \mathrm{MS}$ spectra were identified as associated with "real" particle events during flight 4 , corresponding to $1.26 \%$ of total spectra collected during this flight. (b) As in (a) but for flight 7 on 13 April, 2015. 1055 MS spectra were identified as associated with "real" particle events during flight 7 , corresponding to $0.61 \%$ of total spectra collected during this flight.

(a)

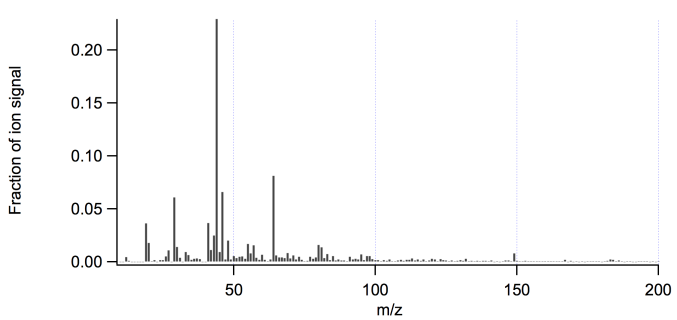

(c)

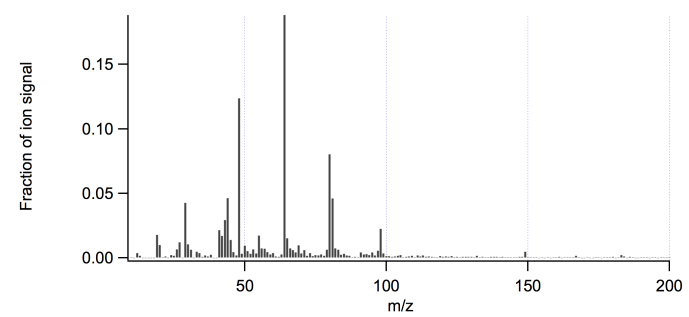

(b)

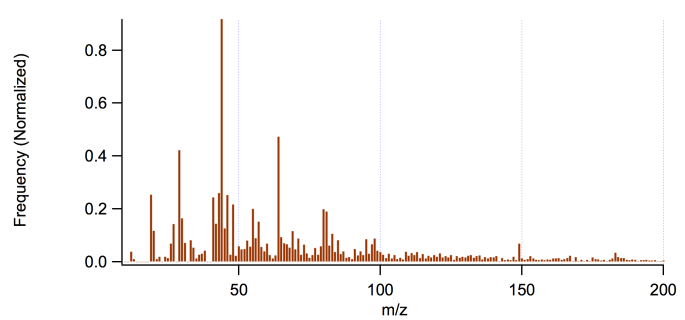

(d)

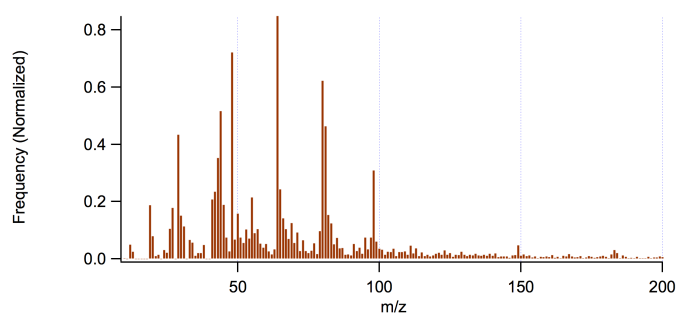

Figure S6: (a) Mean mass spectrum and mass spectral histogram (b) for particle class 1 of the two cluster solution. (c) Mean mass spectrum and mass spectral histogram (d) for particle class 2 of the two cluster solution. 


\section{Supplementary Results}

(a)
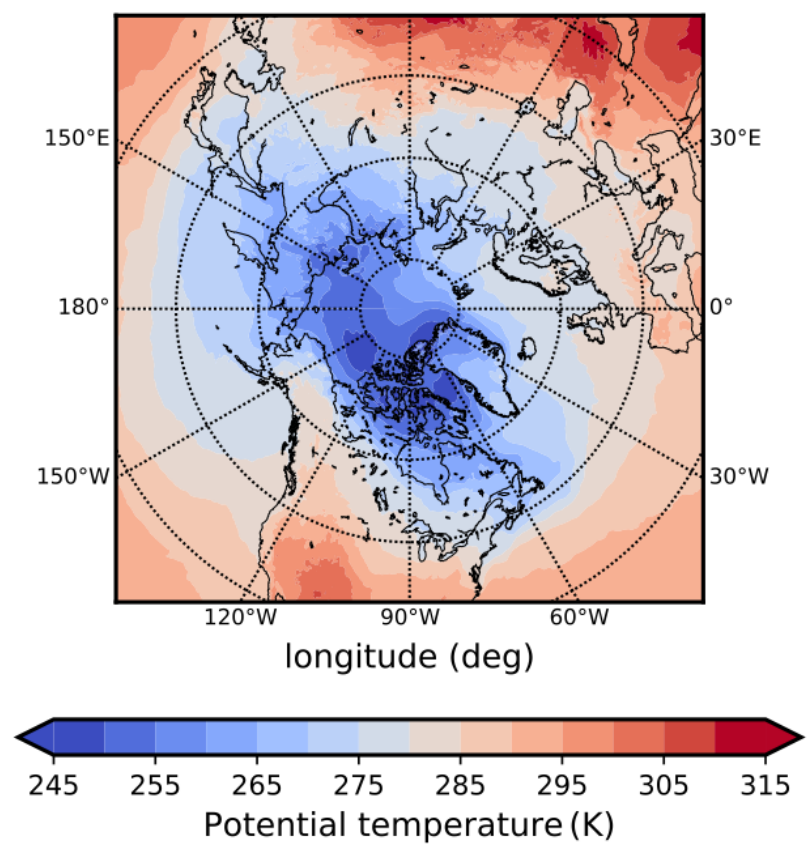

(b)

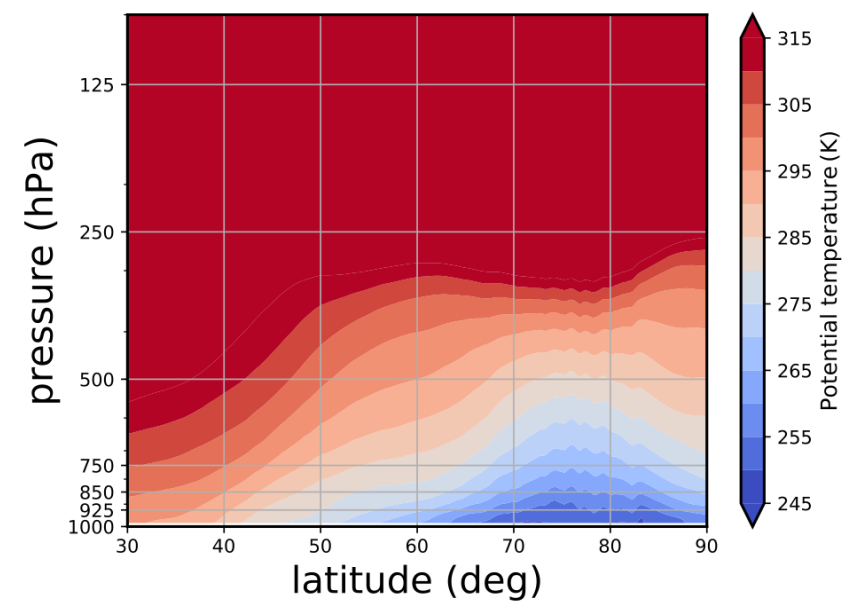

Figure S7: (a) Map of mean potential temperature during 7 - 13 April 2015 from ECMWF. (b) Zonal mean potential temperature from ECMWF during 7 - 13 April 2015, averaged between $-110^{\circ} \mathrm{W}$ and $-60^{\circ} \mathrm{W}$. 


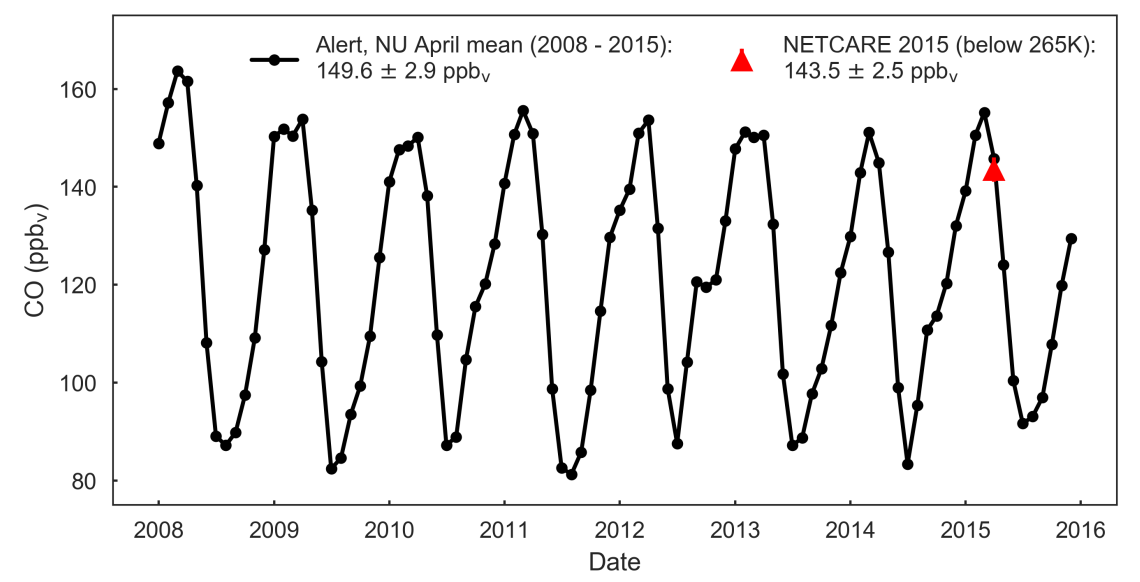

Figure S8: Monthly mean carbon monoxide concentrations at Alert, NU during 2008 2015 (black) (Novelli et al., 2016). The mean ( \pm standard deviation) CO concentrations in April $2008-2015$ at Alert was $149.6 \pm 2.9$ ppbv. The mean ( \pm standard deviation) CO concentration measured during NETCARE 2015, from the surface up to $265 \mathrm{~K}(\sim 1500 \mathrm{~m})$, is shown with the red triangle $(143.5 \pm 2.5 \mathrm{ppbv})$. 
(a)

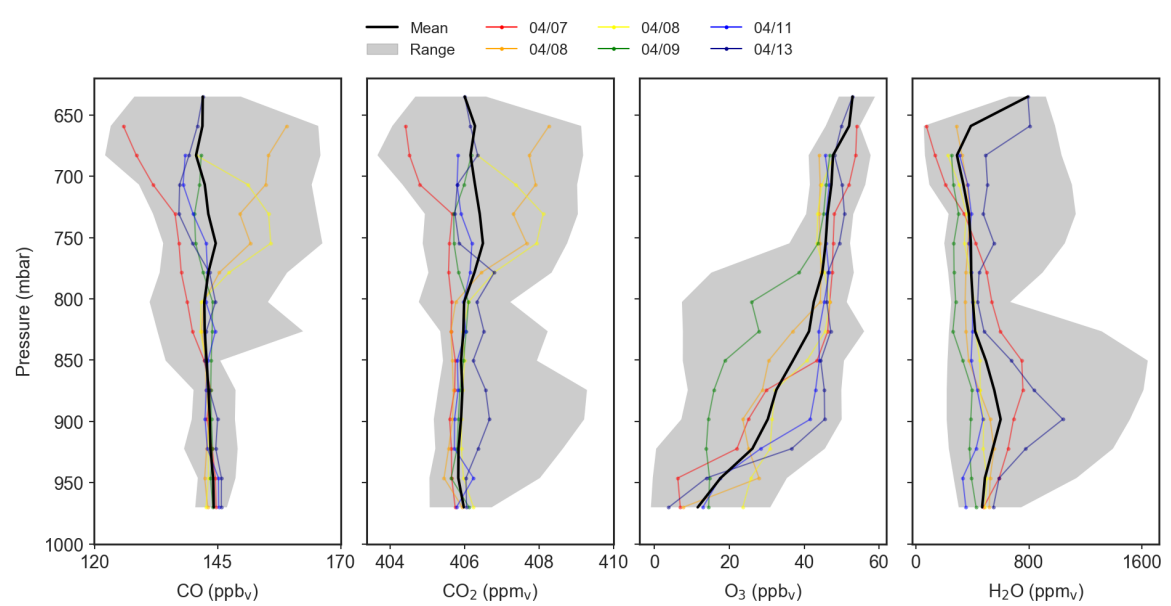

(b)

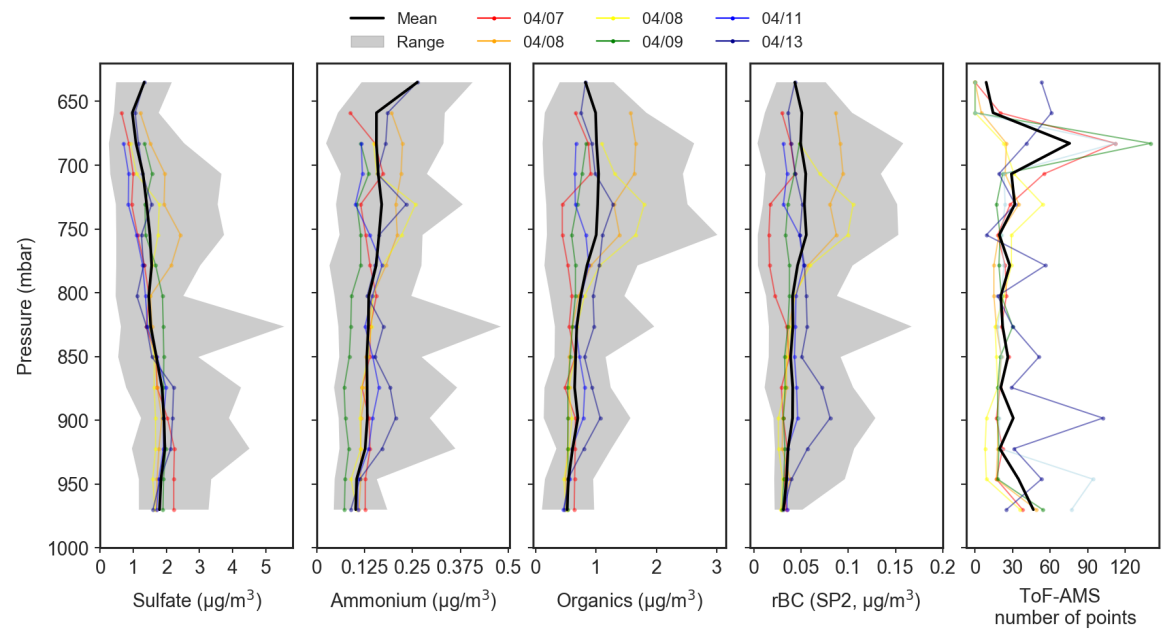

Figure S9: (a) Mean pressure profiles of trace gases in the polar dome observed during $7-13$ April 2015, including carbon monoxide, carbon dioxide, ozone and water vapour. (b) Mean pressure profiles of sub-micron aerosol composition in the polar dome observed during $7-13$ April 2015, including sulphate, organics and ammonium from the ToF-AMS and refractory black carbon (rBC) from the SP2. The profile of number of points represents the number of measurements from the ToF-AMS, which had the slowest sampling rate of all instruments deployed during NETCARE 2015. 


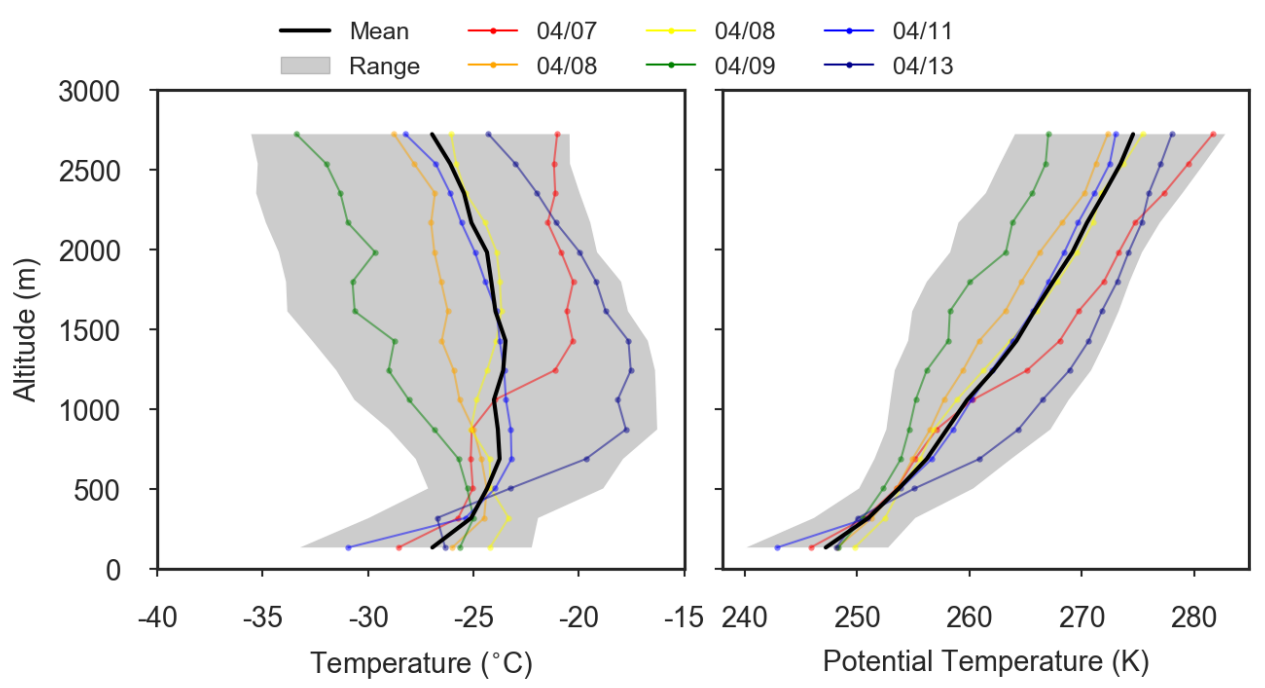

Figure S10: Mean altitude profiles of temperature (left) and potential temperature (right) in the polar dome observed during $7-13$ April 2015. Coloured lines indicate the mean profile for each flight, the black line represents the mean profile over all flights, and gray shading shows the range of observations in each altitude bin.

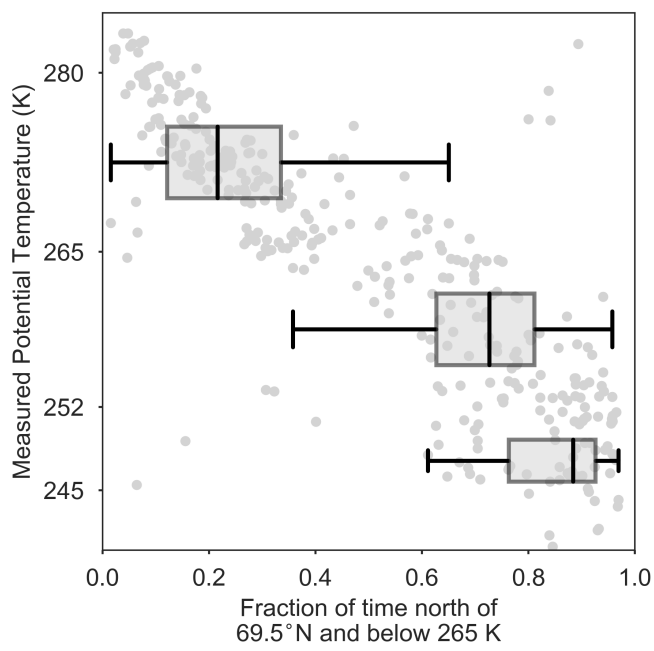

Figure S11: Observed potential temperature $(\mathrm{K})$ as a function of FLEXPART-ECMWF predicted fraction of the past 10 days in the mid-to-lower polar dome (i.e., below $265 \mathrm{~K}$ and north of $\left.69.5^{\circ} \mathrm{N}\right)$. The FLEXPART-ECMWF relative residence time is binned in the lower $(245-252 \mathrm{~K})$, middle $(252-265 \mathrm{~K})$ and upper $(265-280 \mathrm{~K})$ polar dome. 


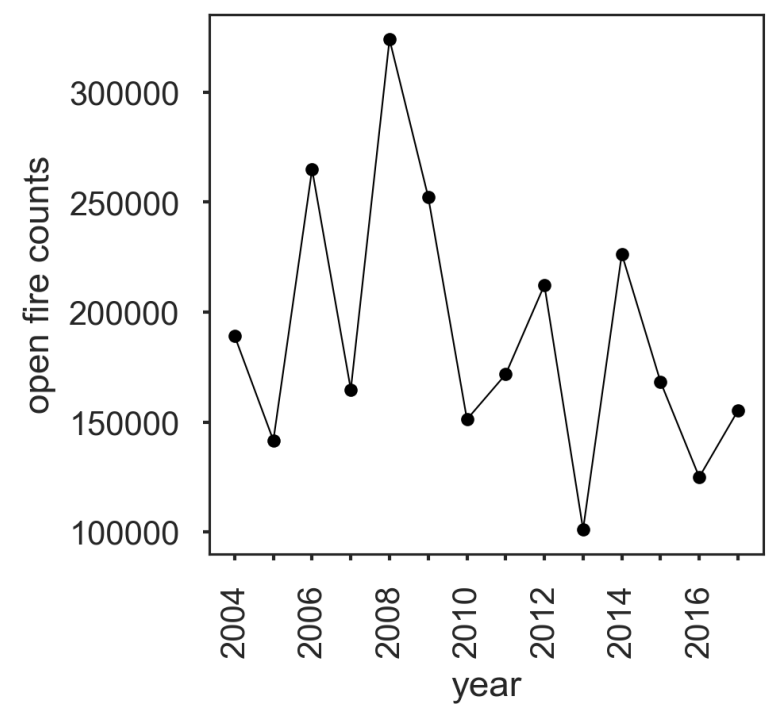

Figure S12: Active fire counts in the Northern Hemisphere north of $35^{\circ} \mathrm{N}$ during March to May for the period 2004 - 2017 from MODIS C6 (obtained from https://firms.modaps.eosdis.nasa.gov/download/)

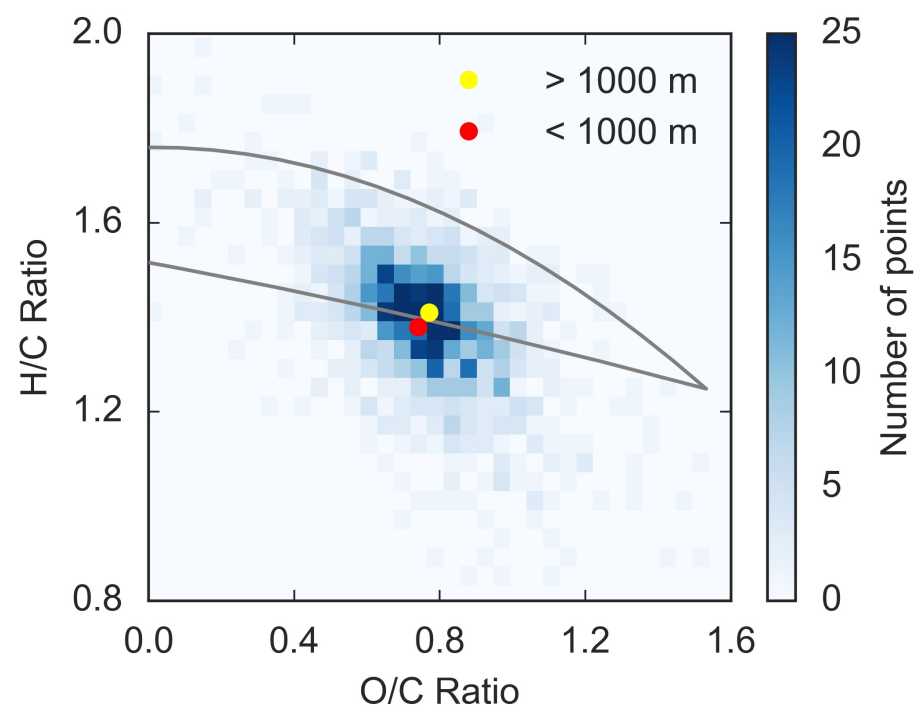

Figure S13: Two dimensional histogram showing the relationship between the oxygen-tocarbon $(\mathrm{O} / \mathrm{C})$ and hydrogen-to-carbon $(\mathrm{H} / \mathrm{C})$ ratio estimated by the ToF-AMS according to the method described in Canagaratna et al. (2015), where the color scale represents the number of observations. Grey lines represent the ambient range observed by $\mathrm{Ng}$ et al. (2011). Red and yellow circles represent the mean $\mathrm{O} / \mathrm{C}$ and $\mathrm{H} / \mathrm{C}$ ratios below and above $1 \mathrm{~km}$, respectively, showing no discernible difference within error. 

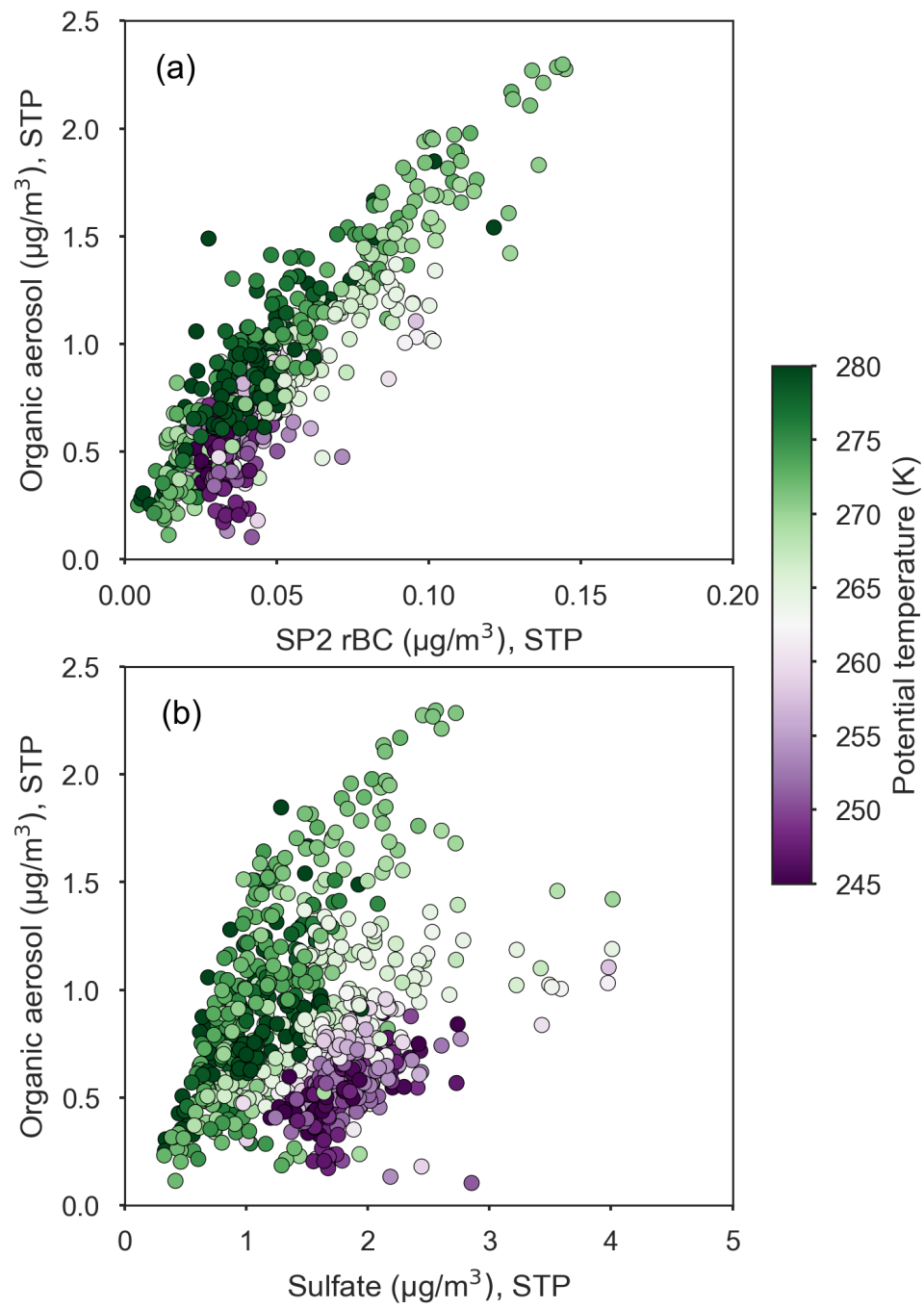

Figure S14: (a) ToF-AMS organic aerosol versus SP2 refractory black carbon (rBC), coloured by measured potential temperature. (b) ToF-AMS organic aerosol versus ToF-AMS sulphate, coloured by measured potential temperature.

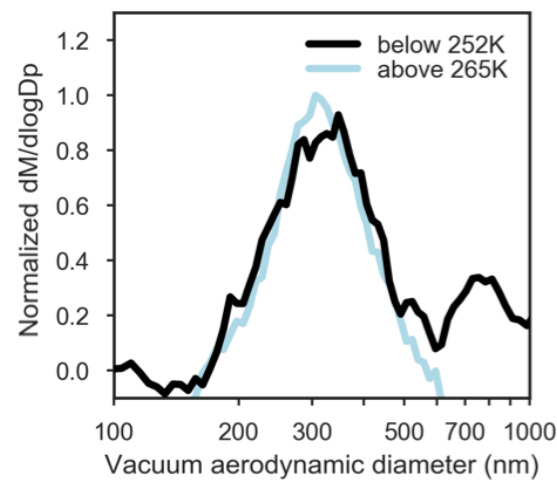

Figure S15: Normalized mean ToF-AMS size distributions of organic aerosol subset by observed potential temperature: below $252 \mathrm{~K}$ (black), above $265 \mathrm{~K}$ (light blue). 

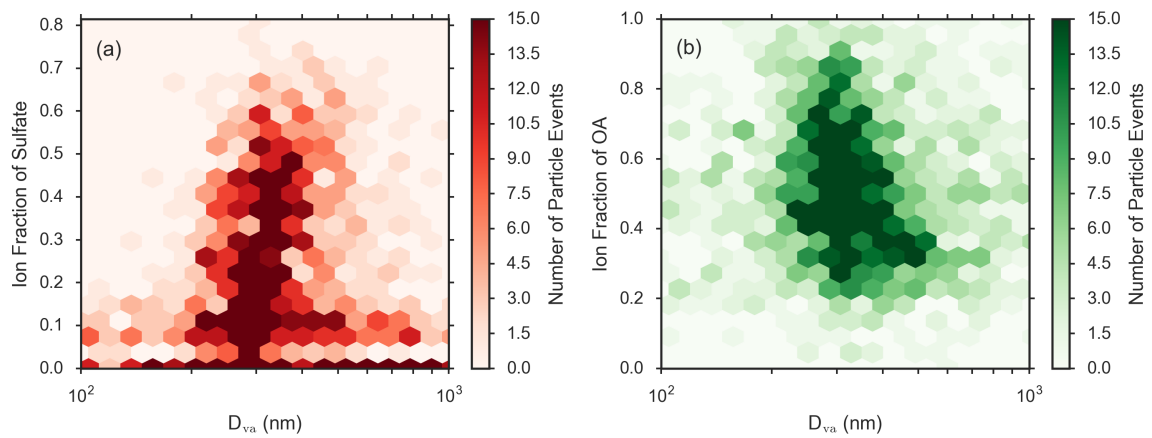

Figure S16: (a) Ion fraction of sulfate in single particle (ETSP) mass spectra as a function of particle size. (b) Ion fraction of total organic aerosol in single particle mass spectra as a function of particle size. The colour scale in both plots represents the number of real particle events observed. A total of 1677 real particle spectra were obtained from the combined observations on two flights (8 April and 13 April, 2015). 


\section{References}

Canagaratna, M. R., Jimenez, J. L., Kroll, J. H., Chen, Q., Kessler, S. H., Massoli, P., Hildebrandt Ruiz, L., Fortner, E., Williams, L. R., Wilson, K. R., Surratt, J. D., Donahue, N. M., Jayne, J. T., and Worsnop, D. R.: Elemental ratio measurements of organic compounds using aerosol mass spectrometry: characterization, improved calibration, and implications, Atmospheric Chemistry and Physics, 15, 253-272, https://doi.org/ 10.5194/acp-15-253-2015, 2015.

Leaitch, W. R., Korolev, A., Aliabadi, A. A., Burkart, J., Willis, M. D., Abbatt, J. P. D., Bozem, H., Hoor, P., Kollnr, F., Schneider, J., Herber, A., Konrad, C., and Brauner, R.: Effects of $20-100 \mathrm{~nm}$ particles on liquid clouds in the clean summertime Arctic, Atmospheric Chemistry and Physics, 16, 11 107-11 124, https://doi.org/10.5194/acp-1611107-2016, 2016.

Ng, N. L., Canagaratna, M. R., Jimenez, J. L., Chhabra, P. S., Seinfeld, J. H., and Worsnop, D. R.: Changes in organic aerosol composition with aging inferred from aerosol mass spectra, Atmospheric Chemistry and Physics, 11, 6465-6474, https://doi.org/10.5194/acp-116465-2011, 2011.

Novelli, P., Crotwell, A., Lang, P., and Mund, J.: Atmospheric Carbon Monoxide Dry Air Mole Fractions from the NOAA ESRL Carbon Cycle Cooperative Global Air Sampling Network, 1988-2015, ftp://aftp.cmdl.noaa.gov/data/trace-gases/co/flask/surface/, 201607-06, 2016.

Willis, M. D., Köllner, F., Burkart, J., Bozem, H., Thomas, J. L., Schneider, J., Aliabadi, A. A., Hoor, P. M., Schulz, H., Herber, A. B., Leaitch, W. R., and Abbatt, J. P. D.: Evidence for marine biogenic influence on summertime Arctic aerosol, Geophysical Research Letters, https://doi.org/10.1002/2017gl073359, 2017. 